\title{
A Study of Mineral Density Surrounding Resorption Sites in Teeth
}

\author{
J. K. AVERY, R. A. MEYERS AND L. E. HALE \\ Department of Oral Biology, School of Dentistry and Department of \\ Anatomy, Medical School, University of Michigan, \\ Ann Arbor, Michigan
}

\begin{abstract}
An investigation of mineral density surrounding lacunar resorption sites in cases of both internal and external root resorption, was carried out on 37 human primary and permanent teeth. In addition, equivalent areas of the roots of 14 normal appearing teeth were studied for comparison. Thirty-two of the teeth were analyzed using microradiographic and microhardness techniques and the remainder were studied microscopically after histologic preparation. The teeth used for microradiographic analysis were embedded in plastic, bisected and half of each tooth was sectioned at 70-100 $\mu$. Microadiographs were taken at $9.5 \mathrm{kv}$ and exposed to 30 milliamperes for 25 to 40 minutes. The other halves of the teeth were used for microhardness tests using a Tukon Microhardness Tester. One series of microhardness measurements was made 10 to $40 \mu$ from sites of active resorption in root dentin and a second series was made 250 to $500 \mu$ from these sites. The hardness measurements of the first series were found to be significantly lower than those of the second in cases of both external and internal resorption. Hardness values of the surface of normal appearing roots were also less than areas 250 to $500 \mu$ deeper in the dentin. Microradiographs did not reveal any definite zone of subsurface demineralization although some resorption sites were bordered by irregular areas of decreased radiodensity which may be due to superimposition of several resorption sites within the thickness of the tooth section. Histologic observations did not reveal a definite subsurface demineralization gradient. The lacunar resorption front was found to be a multilocular and completely interconnected system.
\end{abstract}

The cause of tooth resorption other than that related to the process of eruption and shedding of teeth, has interested numerous investigators for many years. The condition of irregular cavities within teeth resulting in "pink spots" was noted as early as 1890 by Miller, in 1894 by Gaskill and in 1920 by Mummery. There have been numerous studies of the characteristics of this pathologic process as well as a number of investigations concerned with its etiology.

To gain information concerning the prevalence of root resorption Massler and Malone ('54) examined the radiographs of permanent teeth of 708 persons and found $86.4 \%$ of the teeth examined or an average of 16 teeth in each person undergoing resorption to some extent. Thoma ('35) pointed out that tooth resorption may originate either on the internal or the external surfaces of the root. Considering the latter type, Henry and Weinmann ('51) found approximately $77 \%$ of external root resorption occurring in the apical third of the tooth, $20 \%$ in the middle third and only $4 \%$ in the gingival third. It was located most often on the mesial and the buccal surfaces of the roots. They concluded resorption occurs more readily on those root surfaces facing physiologic movement, the areas where trauma was the greatest. They also found, as did Warner et al. ('47) that repair of roots with cementum or dentin-like substance occurred in a high percentage of the cases. Stafne and Slocumb ('44) found the central incisor the most frequently involved tooth. In consideration of causes, most investigators believed trauma was an important factor. This may be caused by occlusal interferences, (Orban, '28) orthodontic appliances, (Ketcham, '29; Hemley, '41; Oppenheim, '42) or chemical agents used in restoring teeth (Via, '55; Cabrini et al., '57; Rabinowitch, '57). Also the prolonged effects of inflammation is believed an important predisposing factor to this disease. Again Cahn ('32) and Scopp ('56) believe that idiopathic resorption may be due to an increase of pulpal blood supply which aids in the resorption 
of calcium salts. Others believe systemic factors, perhaps hormonal, such as hyperthyroidism as suggested by Becks ('33) and by Henry and Weinmann ('51) or hyperparathyroidism which according to Young ('63) may predispose this process in experimental animals. There are many causes of resorption of both the internal and external surfaces of the root however, which cannot be explained by any of the above mentioned causes.

Recently modern scientific methods have been used in an attempt to gain further insight into the etiology of this process. Burstone ('53) found the ground substance of dentin adjacent to the area of internal resorption to contain more than normal amounts of glycoprotein material. $\mathrm{He}$ theorized this increase may be due in part to proteolytic activity of pulpal bacteria superimposed on the primary processes of resorption. Sognnaes ('59) utilizing microradiographic techniques found no evidence of a demineralization gradient in tooth resorption. In 1961 , utilizing electron microscopy, he found a half micron alteration of the dentin surrounding a Howship's lacunae. There has been much work done on bone resorption and several investigations are pertinent to this discussion. Greulich ('61) utilizing high resolution, ultrasoft microradiography studied the distribution of organic mass at the sites of bone resorption. He observed a band or rind approximately $1-1.5 \mu$ in width at the point of junction of the osteoclast. Goldhaber and Barrnett ('60) demonstrated succinic dehydrogenase in osteoclasts and Burstone ('60) found dehydrogenase, acid phosphatase and leucine aminopeptidase in osteoclasts. Balough ('63) found osteoclasts to contain DPNH diaphorase, TPNH diaphorase, lactic and succinic dehydrogenase. Fullmer ('64) also noted osteoclasts contain high amounts of the latter. Ultrastructural studies by Hancox and Boothroyd ('63) revealed mineral crystals in the vacuoles of the osteoclasts and the resulting exposed collagen was noted to be enclosed in the folds of the cells' ruffled border. It was suggested that an initial mineral loss is followed by digestion of the fibrous matrix.
In an attempt to gain furher information of the characteristics of the mineral density of the calcified tissue surrounding lacunar resorption sites in dentin, the present study was planned and has employed microradiographic, microhardness and histologic techniques.

\section{MATERIALS AND METHODS}

\section{A. Microradiography}

Thirty-two primary and permanent teeth showing areas of external and internal resorption were fixed in 10\% neutral formalin and then embedded in bioplastic. The teeth were then cut in half, one half being used for microhardness studies and the other half for microradiography. Sections were cut for microardiography on a water cooled, hard tissue sectioning machine ${ }^{1}$ at $70-100 \mu$. The thickness of each section was measured with a micrometer to determine the proper time for radiographic exposure. These were stored in tap water until they were used. At that time they were allowed to air dry for 5-10 minutes, the excess bioplastic removed from the sections and then they were cemented with acetone onto Saran Wrap which had been cut into strips. These strips bearing the sections were adapted onto $1 \times 3$ spectroscopic plates ${ }^{2}$ in the dark room. These plates were placed in a camera bottom so that the source-object distance was $\mathbf{5 . 5}$ inches. A shutter was used with a film holder to make the bottom light tight so the film could be carried to and from the machine and the dark room.

The x-ray machine used was a Picker 50 K.V. industrial unit with a type AEG 50 machlett tube operated at 38 primary volts and 30 milliamperes which produced $9.5 \mathrm{~K} . \mathrm{V}$. This voltage gives $\mathrm{x}$-rays of a wave length of approximately $2.2 \mathrm{~A}$ which is the proper wave length for maximal absorption by calcium ions. Exposures varied from 25-40 minutes depending upon the thickness of the sections. After exposures were made the plates were developed in Kodak D-19 at $68^{\circ} \mathrm{F}$ for five minutes, washed, fixed and dried. They were studied and photographed on a microscope. ${ }^{1}$ Gillings Hamco Thin Sectioning Machine, Hamco
Machines Inc., Rochester, New York.

2 Kodak type 649-0. 


\section{B. Microhardness}

The undecalcified halves of the teeth used for microhardness were sliced into slabs averaging one-half millimeter thick and smoothed by hand on a glass slab using no. 60 wet sand paper. Final polishing was accomplished with a felt wheel at high speed for ten seconds. The sections were then affixed to glass slides and tested for microhardness ${ }^{3}$ using a 25 gm weight. The instrument was standardized each day to assure consistent results. Only uniform indentations showing diamond-shaped impressions with the long axis seven times greater than the width were used. The areas considered to be undergoing resorption, were those showing obvious scalloping either on the internal or external surfaces of the tooth root. The diamond indenter was positioned to gain measurements in two areas. The first area was as close as possible to the zones of resorption. These were all within $10-40 \mu$ from these sites. A second area studied for comparison was 250 to $500 \mu$ from these areas. To facilitate interpretation of the areas of the crown measured, the tooth sections were magnified and tracings of each section were made. Another series of five normal appearing teeth were studied in the same manner. The hardness of the root surface area underlying cementum was compared to an area again 250 to $500 \mu$ away in the dentin.

\section{Histologic}

Another series of normal appearing human teeth and some undergoing resorption were fixed in formalin, decalcified with formic citrate and then sectioned, mounted, stained with hemotoxylin and eosin and Mallory's connective tissue stain and examined microscopically. Attempts were made to examine similar areas as evaluated by the microradiographic and hardness techniques. Photomicrographs were then made of sections believed pertinant to this study.

\section{RESULTS}

\section{Microhardness study}

The average mean Knoop hardness (KHN) of dentin 10 to $40 \mu$ from sites of active root resorption was found to be
37.6 in primary teeth and 43.1 in permanent teeth or an average of $40.4 \mathrm{KHN}$ for both series of teeth. The KHN of dentin 250 to $500 \mu$ from these zones was found to be 52.8 in primary teeth and 56.1 in permanent teeth. It is observed that this is a difference of $15.2 \mathrm{KHN}$ in primary teeth and 13.0 in permanent teeth between the areas of resorption and the areas deeper in dentin. An explanation of these findings is shown in figures 1,2 and 3 and in tables 1 and 2.

A test of the significance of the hardness of the dentin at the resorption fronts as compared to areas of non-resorbing dentin was done by calculating the " $T$ " values of the mean hardness of the two areas in each individual tooth. Most of them were found to be significantly different at the 95\% level of confidence. Also the teeth were found to show some variation in hardness within the two locations studied. It was noted that the mean hardness of the resorbed area in permanent teeth was greater than that of the primary teeth by only $5.5 \mathrm{KHN}$ and in the non-resorbed area $3.3 \mathrm{KHN}$. There was an indication of a slightly increased hardness of the permanent dentition over the primary.

In an attempt to gain more information about the characteristics of the surface as opposed to deeper areas in dentin, it was decided to analyze a series of normal appearing teeth. Five teeth with normal appearing roots were prepared in the manner previously indicated and indentations were made $10-40 \mu$ from the surface of the root dentin immediately underlying the cementum. A second series of indentations were obtained 250 to $500 \mu$ deeper in the dentin. The surface dentin underlying cementum was found to be less hard than that situated deeper in the root (table 3 and fig. 4). An average mean hardness of $42.0 \mathrm{KHN}$ was found for the surface and $62.2 \mathrm{KHN}$ for the deeper dentin or a difference of 20.2 Knoop Hardness Numbers. Using a one way analysis of variants the $\mathrm{F}$ ratio revealed this difference between the means to be significant at the $99 \%$ confidence level. There appears thus to be a band of softer peripheral dentin of the root underlying the cementum. The

\footnotetext{
3 Tukon Microhardness Tester with Knoop Diamond Indenter.
} 
TABLE 1

Primary teeth

\begin{tabular}{|c|c|c|c|c|c|c|c|c|}
\hline \multirow{2}{*}{$\begin{array}{l}\text { Tooth } \\
\text { no. }\end{array}$} & \multicolumn{3}{|c|}{ Resorbed areas } & \multicolumn{3}{|c|}{ Non-resorbed areas } & \multicolumn{2}{|c|}{ Calculations } \\
\hline & $\begin{array}{l}\text { No. of } \\
\text { indents }\end{array}$ & KHN & S.D. & $\begin{array}{l}\text { No. of } \\
\text { indents }\end{array}$ & KHN & S.D. & "T" value & Signif. \\
\hline D-1 & 26 & 30.6 & 5.9 & 8 & 40.9 & 3.0 & 3.6 & yes \\
\hline D-2 & 30 & 29.9 & 2.1 & 8 & 43.3 & 1.3 & 7.8 & yes \\
\hline D-3 & 19 & 31.7 & 7.9 & 5 & 58.8 & 2.3 & 3.9 & yes \\
\hline $\mathrm{D}-4$ & 32 & 31.0 & 7.9 & 8 & 41.8 & 3.5 & 3.6 & yes \\
\hline D-5 & 37 & 35.1 & 3.2 & 13 & 45.8 & 1.0 & 8.2 & yes \\
\hline D-6 & 34 & 31.9 & 3.6 & 12 & 45.7 & 4.2 & 3.3 & yes \\
\hline $\mathrm{D}-7$ & 13 & 31.8 & 2.0 & 11 & 54.0 & 4.8 & 6.1 & yes \\
\hline D-8 & 20 & 29.1 & 2.8 & 10 & 56.6 & 4.1 & 20.7 & yes \\
\hline D-9 & 21 & 38.6 & 4.5 & 12 & 61.9 & 6.3 & 7.8 & yes \\
\hline M-1 & 25 & 52.2 & 10.2 & 29 & 58.5 & 13.1 & 1.9 & no \\
\hline M-2 & 15 & 45.1 & 6.3 & 24 & 58.2 & 11.3 & 3.9 & yes \\
\hline M-3 & 16 & 44.5 & 17.3 & 27 & 50.0 & 12.4 & 1.3 & no \\
\hline M-4 & 11 & 45.5 & 14.5 & 17 & 53.2 & 14.3 & 1.3 & no \\
\hline M-5 & 25 & 41.8 & 10.7 & 16 & 51.4 & 15.1 & 2.1 & yes \\
\hline C-1 & 27 & 55.2 & 13.4 & 17 & 55.5 & 14.2 & 0.08 & no \\
\hline Total & 351 & & & 217 & & & & \\
\hline Average & & 37.6 & & & 52.8 & & & \\
\hline
\end{tabular}

TABLE 2

Permanent teeth

\begin{tabular}{|c|c|c|c|c|c|c|c|c|}
\hline \multirow{2}{*}{$\begin{array}{c}\text { Tooth } \\
\text { no. }\end{array}$} & \multicolumn{3}{|c|}{ Resorbed areas } & \multicolumn{3}{|c|}{ Non-resorbed areas } & \multicolumn{2}{|c|}{ Calculations } \\
\hline & $\begin{array}{l}\text { No. of } \\
\text { indents }\end{array}$ & KHN & S.D. & $\begin{array}{c}\text { No. of } \\
\text { indents }\end{array}$ & KHN & S.D. & "T" value & Signif. \\
\hline IR-12 area 1 & 28 & 49.9 & 7.7 & 9 & 55.6 & 6.7 & 1.5 & no \\
\hline IR-12 area 2 & 33 & 44.9 & 3.6 & 10 & 56.9 & 4.0 & 6.5 & yes \\
\hline IR-13 & 16 & 39.8 & 4.2 & 11 & 54.6 & 3.7 & 7.2 & yes \\
\hline IR-14 & 28 & 53.1 & 8.1 & 13 & 59.7 & 2.3 & 2.7 & yes \\
\hline IR-15 & 10 & 33.6 & 2.2 & 10 & 60.3 & 4.0 & 73.1 & yes \\
\hline IR-16 area 1 & 24 & 36.5 & 2.7 & 10 & 58.3 & 1.1 & 7.5 & yes \\
\hline IR-16 area 2 & 20 & 31.8 & 2.9 & 14 & 48.9 & 2.9 & 16.3 & yes \\
\hline Total & 159 & & & 77 & & & & \\
\hline Average & & 43.1 & & & 56.1 & & & \\
\hline
\end{tabular}

TABLE 3

Permanent teeth. Normal appearing root dentin

\begin{tabular}{|c|c|c|c|c|c|c|}
\hline \multirow{2}{*}{$\begin{array}{c}\text { Tooth } \\
\text { no. }\end{array}$} & \multicolumn{3}{|c|}{ Surface } & \multicolumn{3}{|c|}{ Below surface } \\
\hline & $\begin{array}{l}\text { No. of } \\
\text { indents }\end{array}$ & KHN & S.D. & $\begin{array}{c}\text { No. of } \\
\text { indents }\end{array}$ & KHN & S.D. \\
\hline N-1 & 28 & 36.1 & 4.6 & 28 & 64.0 & 6.4 \\
\hline N-2 & 17 & 43.5 & 4.0 & 17 & 59.0 & 6.1 \\
\hline N-3 & 26 & 43.8 & 3.6 & 26 & 62.9 & 5.3 \\
\hline$N-4$ & 26 & 43.8 & 5.5 & 26 & 65.4 & 7.1 \\
\hline N-5 & 14 & 43.1 & 8.3 & 14 & 59.8 & 5.3 \\
\hline Total & 111 & & & 111 & & \\
\hline Average & & 42.1 & & & 62.2 & \\
\hline
\end{tabular}


surface measurements of both series of permanent teeth at 10 to $40 \mu$ from the surface of dentin were found to have very similar hardness values. The normal appearing surface was $42.0 \mathrm{KHN}$ and the abnormal 43.1 KHN.

It is of interest that because of the extent of resorption, the location of some of the microhardness measurements were located near central root dentin or the area where the hardness was originally the greatest.

\section{Microradiographic study}

Microradiographs of the $70-100 \mu$ thick dentin specimens revealed the oval shape of the resorption cavities and the interrelationship of large groups of these spaces (figs. 5,6). It is of interest to observe that as many as 50 to 75 may be present in the thickness of a 70-100 $\mu$ slab. Many of the lacunae appear to range from 30 to $200 \mu$ or more in size and in some cases a number of smaller ones appear in contact with a larger cavity (fig. 6). The larger cavity may be termed "primary" sites and the smaller lacunae associated with the larger areas "secondary" sites. The multilocular areas in figures 5 and 6 reveal how a number of lacunae may be grouped, many of them appear superimposed in the radiograph. No evidence appears of a gradient of mineral resorption around the sites. The resorption cavities shown in figures 5 and 6 were from a case where little tissue destruction had occurred. This could be considered a young active site. The lacunae appear smaller and more numerous than those of figures 7 and 8 . The site shown in figure 7 is from an advanced case of internal resorption and much dentin was missing. This probably is an older site which has lost some of the spicules of dentin which helped define the smaller sites. As these sites expanded the spicules are eliminated resulting in the formation of larger sites. The edges of the resorption cavities appear equally as dense as the adjacent areas with the exception of the small area appearing in the center and upper left of figure 7 . This area again may consist of a number of smaller sites, however, which are associated with the adjacent larger one. The microradiograph shown as figure 8 is of a deep, tunnel-type defect. This kind of defect was found in several of the teeth and is thought to be related to an accessory root canal. This theory is substantiated by the fact that this microradiograph was taken of an area near the apical canal. The boundaries of this space appear to be altered by numerous small lacunar sites. Many of the resorption fronts revealed areas of repair. Microradiographic appearance of areas of secondary deposition of bony or cementum-like susbtance on the root surface are shown in figures 9 and 10. Figure 9 is from an area of internal resorption and figure 10 from an external site. In a few areas, what appeared as a subsurface demineralization front was observed (fig. 11). As this is from an area of internal resorption, it is possible that the less radiopaque area represents predentin. A possible similar area can be seen in figure 13 where the resorption is in an early stage and some of the predentin is still present. Predentin is quite radiolucent and may appear as shown in figure 13. The diagram shown in figure 12 is an interpretation of the multilocular nature of the resorption sites and their various means of communication. All of the sites are connected with the surface of the advancing front and each site is usually connected with the smaller ones above, below and/or the one to the right and left of it. By this means a vast surface area is maintained and small islands of dentin are produced and efficiently eliminated.

\section{Histologic study}

The microscopic studies were of teeth some with internal and others with external resorption sites and the observations clarified some of the previous findings. Figure 13, as previously noted, was a primary site probably caused by chemical trauma on the pulp, $\mathrm{Ca}(\mathrm{OH})_{2}$. The initial stage of resorption is indicated by the degenerating odontoblasts and little loss of tissue at this time except the uncalcified predentin. It also appears that predentin deposition has ceased. Figure 14 illustrates a dense staining zone bordering a resorption site and may be indicative of such chemical changes as mineral loss to the depth of several microns. Functional dentin appears on the right with the proto- 
plasmic processes of the odontoblasts still in the dentinal tubules. Figures 15 and 16 both are from early and acutely active resorption fronts. In both figures observe the area of predentin (P) still present along the pulp border. It is apparent how this zone is bypassed along with an attached spicule of dentin as the front moves deep into the tissue. Close association of cells in the lacunae and the fibrous appearing substance in the background is evident. Finally, no definite subsurface alteration was revealed in the histologic study.

\section{DISCUSSION}

Analysis of the mineral density at 10 to $40 \mu$ from lacunar resorption sites by microhardness measurements revealed a significant decrease in amount. If this is a stage in this pathologic process then it should be considered relative to the series of events that characterize resorption. Before doing this it is best to consider several technical factors that might lead to misinterpretation of the data. First, it is possible to produce a curved surface on the edge of a bone or tooth sample bordered by a softer substance such as plastic by over polishing. It has been noted by other investigators, Craig and Peyton ('58) and Rautiola and Craig ('61) that curved surfaces may produce distorted indentations. In the present study several precautions were taken to prevent this possible error. (1) Polishing was limited to ten seconds and (2) only diamond shaped indentations in which the long axis was seven times the width were used. Any distortion in this pattern caused immediate rejection of the measurement. Again possible false readings might be obtained from measurements taken in an area undermined with resorption sites. However only a few of the teeth were noted to be affected in this manner as discussed in the microradiographic findings. Measurements in such areas could produce distorted impressions yet few were obtained and these were excluded from the study.

The finding of less hard peripheral dentin underlying cementum in normal appearing roots is in agreement with the findings of Rautiola and Craig ('61). They found a narrow band of peripheral dentin located between the central root and cementum to have a KHN of 38 . Central root dentin on the other hand, had a mean KHN of 69. These figures for permanent teeth agree closely with the findings in the present study of normal permanent teeth which was $42 \mathrm{KHN}$ for peripheral dentin and $62 \mathrm{KHN}$ for areas of one-fourth to onehalf millimeter nearer the central root. These are also similar to the findings of 56 KHN for non-resorbed areas of the pathologic permanent teeth. Again the extent of resorption in each tooth was different so the location of the hardness measurements would vary. In one case the resorption front would be located in central root dentin and in the next it would be nearer the periphery. That is why no overall statistical correlations were attempted, only the statistical difference between each resorption site and the area deeper in the same tooth. It is of interest that 17 to 22 resorbing teeth showed significant differences in the hardness of the two areas. Therefore if all technical errors have been excluded it is possible that a subsurface demineralization gradient exists. Such a gradient of 10 to $40 \mu$ was not apparent microradiographically although it has been shown previously by Avery et al. ('61) that Tukon microhardness measurements reflect changes in mineral density that are not discernable by microradiography. This is true at least under the limitations of the equipment and techniques used.

Other investigators have noted the surface of root dentin to be less hard. It has been termed the "granular layer" as it appears microscopically to contain interglobular spaces. It is described as a developmental feature by Orban ('62).

Resorption of mineral to the depth of 1 to $2 \mu$ have been described by a number of authors. Sognnaes et al. ('61) with the electron microscope described the characteristics of resorption surfaces of dentin and noted distinct ultrastructural changes to the depth of $0.6 \mu$. This change involved a reduced electron density and evidence of denuded fibrillar material. $\mathrm{He}$ stated he found no evidence of demineralization beyond the half micron. He also stated this in an earlier study in 1959 in which he used microadiography. The ultra- 
structural studies of Hancox and Bothroyd ('63) on avian bone revealed a mineral loss lining a lacunae. Further, they found crystals in the vacuoles of the osteoclasts and exposed collagen fibrils were found enclosed in the folds of the cell membrane. They believe this is suggestive of a process of continuous digestion. Other investigators who have not found demineralized collagen fibers believe the primary change to be solution of the collagen fibers: Scott and Pease ('56); Gonzales and Karnovsky ('61)); and Dudley and Spiro ('61).

Whether the mechanism involves first the alteration of the collagen fibril resulting in a subsequent release of mineral and final digestion of the fibril or vice versa is yet to be answered. It is hoped the present observations of a possible subsurface demineralization front may aid in the clarification of this complex process.

\section{CONCLUSIONS}

1. The microhardness 10 to $40 \mu$ from lacunar resorption sites was consistently less than that of dentin 250 to $500 \mu$ from these sites.

2. The various amounts of root dentin lost during resorption resulted in measurements of some lucunar sites which were located in areas previously highest in mineral density.

3. Microhardness of normal appearing dentin 10 to $40 \mu$ near the root surface was consistently less than that of dentin 250 to $500 \mu$ from these sites.

4. Microradiographs of resorption sites revealed some to be bordered by irregular areas of decreased radiodensity which was believed to be caused by superimposition of several resorption sites in the thickness of the slab or to zones of predentin.

5. Microradiographs of resorption sites in dentin revealed the lacunae to be oval shaped, multilocular and a completely inter connected system, with themselves and with the surface of the front.

\section{Author's Note}

The authors would like to dedicate this paper to Professor Wilfrid T. Dempster, a friend, an associate and a constant inspiration in teaching and research.

\section{LITERATURE CITED}

Avery, J. K., R. L. Visser and D. E. Knapp 1961 The pattern of the mineralization of enamel. J. Dent. Res., 40: 1004-1019.

Balogh, K. J. 1963 Histochemical study of oxidative enzyme systems in teeth and perio dontal tissues. J. Dent. Res., 42: 1457-1466.

Becks, H. 1933 Root resorptions and their relation to pathologic bone formations I. Statistical data and roentogenographic aspect. Am. Soc. Ortho., 33: 84-121.

Burstone, M. S. 1953 The ground substance of abnormal dentin, secondary dentin, and pulp calcification. J. Dent. Res., 32: 269-279. - 1960 Hydrolytic enzymes in dentinogenesis and osteogenesis. In: Calcification in Biological Systems. Ed., R. F. Sognnaes. Publication No. 64 of the A.A.A.S., Washington, pp. 217-243.

Cabrini, R. I., O. A. Maisto and E. E. Manfredi 1957 Internal resorption of dentine, Oral Surg., oral Med., and Oral Path., 10: 90-96.

Cahn, L. R. 1932 A case of bone metaplasia in the pulp canal of a tooth. Dent. Items of Interest, 54: 518-520.

Craig, R. G., and F. A. Peyton 1958 The microhardness of enamel and dentin. J. of Dent. Res., 37: 661-668.

Dudley, H. R., and D. Spiro 1961 The fine structure of bone cells. J. Biophys. and Biochem. Cytol., 11: 627-649.

Fullmer, H. M., C. C. Link and M. J. Baer 1964 A stain for bone - Illustrating apposition and absorption in two colors. Stain Tech., 39: 7173.

Gaskill, H. J. 1894 Report of a case in which dentine of a tooth was absorbed by the pulp. Dental Cosmos., 36: 1019-1020.

Goldhaber, P., and R. J. Barrnett 1960 Succinic dehydrogenase in osteoclasts in resorbing-bone tissue cultures. J. Dent. Res., 39: 728.

Gonzalez, F. and M. J. Karnovsky 1961 Electron microscopy of osteoclasts in healing fractures of rat bone. J. Biophys. and Biochem. Cytol., 9: 299-316.

Greulich, R. G. 1961 Organic mass distribution in bone matrix undergoing osteoclastic resorption. Arch Oral Biol., 3: 137-142.

Hancox, N. M., and B. Boothroyd 1963 Structure-function relationship in the osteoclast. In: Mechanisms of Hard Tissue Destruction. Ed., R. F. Sognnaes. Am. Assoc. for Adv. of Science, Washington. Chapter 18, 497-514.

Hemley, S. 1941 The incidence of root resorption of vital permanent teeth. J. Dent. Res., 20: 133-141.

Henry, J. L., and J. P. Weinmann 1951 The pattern of resorption and repair of human cementum. J. Am. Dent. Assoc., 42: 270-290.

Ketcham, A. H. 1929 A progress report of an investigation of apical root resorption of vital permanent teeth. Inter. J. Ortho., 15: 310-328.

Massler, M., and A. J. Malone 1954 Root resorption in human permanent teeth, a roentogenographic study. Am. J. Ortho, 40: 619633. 
Miller, W. D. 1890 Action of the products of fermentation of the different structures of the mouth. S. S. White Dental Mfg. Co., Philadelphia. Chapter 6, 123.

Mummery, J. H. 1920 The pathology of "pink spots" on teeth. Brit. Dent. J., 41: 301-311.

Oppenheim, A. 1942 Human tissue response to orthodontic intervention of short and long duration. Am. J. Ortho, and Oral Surg., 28: 263-301.

Orban, B. 1928 Tissue changes in traumatic occlusion. J. Am. Dent. Assoc., 15: 2090-2106.

1962 Dentin. In: Orban's Oral Histology and Embryology. Ed., H. Sicher. C. V. Mosby Co., St. Louis. Chapter IV, 120.

Rabinowitch, B. Z. 1957 Internal resorption. Oral Surg., Oral Med., Oral Path., 10: 193206.

Rautiola, C. A., and R. G. Craig 1961 The microhardness of cementum and underlying dentin of normal teeth and teeth exposed to poriodontal disease. J. Perio., 32: 113-123.

Scopp, I. W. 1956 Resorption of dentin and cementum in teeth. J. Dent. Med., 11: 220224.

Scott, B. L., and D. C. Pease 1956 Electron microscopy of the epiphyseal apparatus. Anat. Rec., 126: 465-495.
Sognnaes, R. F. 1959 Microradiographic observations of demineralization gradients in the pathogenesis of hard-tissue destruction. Arch. Oral Biol., 1: 106-121.

Sognnaes, R. F., J. T. Albright and R. M. Frank 1961 Electron-microscopic surface changes in lacunar resorption. Inter. Assoc. Dent. Res., Abstracts 39th Gen. Meeting, J. Dent. Res., 40: 672 .

Stafne, E. C., and C. H. Slocumb 1944 Idiopathic resorption of teeth. Am. J. Ortho. and Oral Surg., 30: 41-49.

Thoma, K. H. 1935 Central osteoclastic resorption of dentine and complete repair with osteo-dentine in the permanent tooth of an adult. Dental Items of Interest, 57: 28-38.

Warner, G. R., B. Orban, M. K. Heine and B. T. Ritchey 1947 Internal resorption of teeth: Interpretation of histologic findings. J. Am. Dent. Assoc., 34: 468-483.

Via, W. F. 1955 Evaluation of deciduous molars treated by pulpotomy and calcium hydroxide. J. Am. Dent. Assoc., 50: 34-43.

Young, R. W. 1963 Histophysical studies on bone cells and bone resorption. In: Mechanisms of Hard Tissue Destruction. Ed. R. F. Sognnaes. Am. Assoc. for Adv. of Science, Washington. Chapter 17, 417-496.

\title{
PLATE 1
}

\author{
EXPLANATION OF FIGURES
}

Figures 1 thru 4 are projection diagrams of sections of human teeth to show the location of the microhardness measurements. The area indicated by the lower series of numbers was taken within $10-40 \mu$ from resorption sites as seen in figures 1,2 and 3 and $10-40 \mu$ from the surface of the normal appearing root in figure 4 . The higher series of numbers were taken one-fourth to one-half millimeter from these areas. The figures are expressed as Knoop Hardness Numbers.

1 A primary molar undergoing external resorption probably related to the process of eruption of its permanent successor. Orig. Mag. $\times 4$.

2 A primary molar tooth undergoing external resorption of the lateral surface of only one root. Orig. Mag. $\times 4$.

3 A projection diagram of a human permanent tooth undergoing internal resorption. The superficial zone adjacent to the pulp has smaller Knoop Hardness Number indicating it is not as hard as the deeper dentin seen. Orig. Mag. $\times 4$.

4 A projection diagram of a normal appearing human tooth. In this case the peripheral zone of the root dentin immediately underlying the cementum was found to be softer than adjacent deeper root dentin. orig. Mag. $\times 4$. 


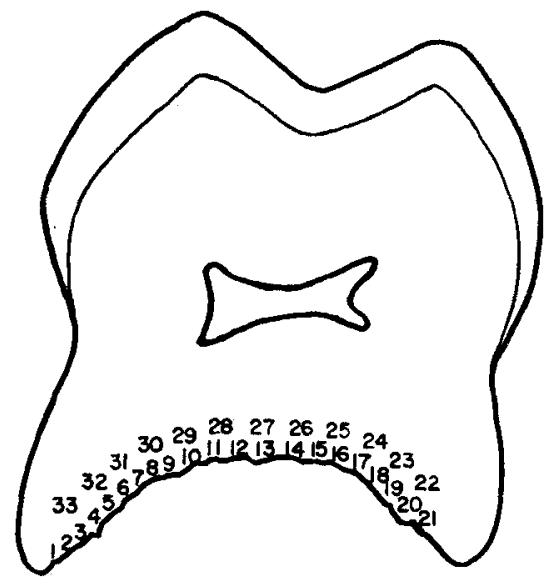

Knoop Hardness Numbers

$\begin{array}{clllll}\text { 1. } 32.8 & 12 . & 33.3 & 23 . & 56.6 \\ \text { 2. } 47.6 & 13 . & 37.8 & 24 . & 56.6 \\ 3 . & 40.7 & 14 . & 37.3 & 25 . & 56.6 \\ 4 . & 40.1 & 15 . & 38.9 & 26 . & 56.6 \\ 5 . & 46.9 & 16 . & 37.8 & 27 . & 56.6 \\ 6 . & 37.3 & 17 . & 40.7 & 28 . & 61.9 \\ 7 . & 26.0 & 18 . & 45.4 & 29 . & 69.6 \\ 8 . & 39.5 & 19 . & 37.3 & 30 . & 68.2 \\ 9 . & 38.9 & 20 . & 36.2 & 31 . & 69.6 \\ 10 . & 39.5 & 21 . & 39.5 & 32 . & 69.2 \\ 11 . & 38.3 & 22 & 53.7 & 33 . & 69.2\end{array}$

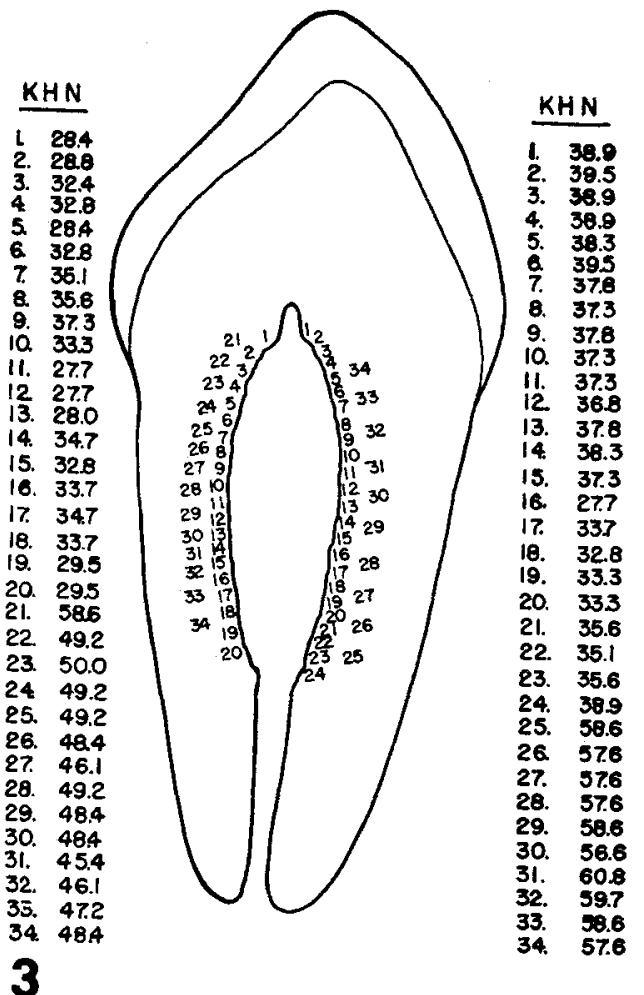

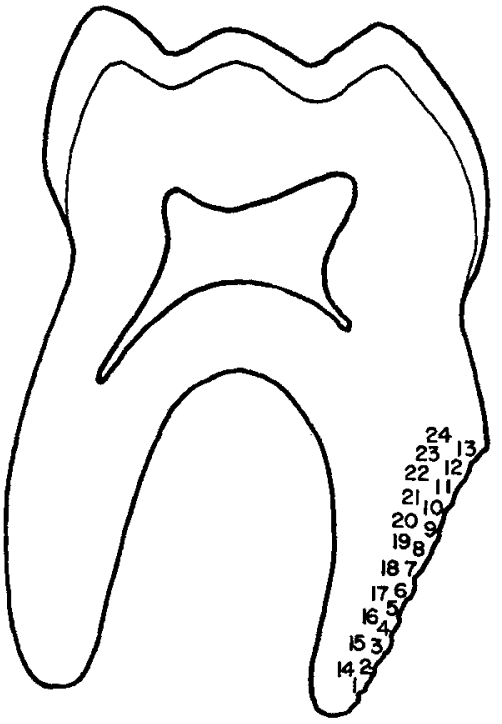

Knoop Hardness Numbers

$\begin{array}{llll}\text { 1. } 23.4 & 9.24 .2 & 17 . & 41.9 \\ \text { 2. } 23.4 & 10.24 .0 & 18 . & 36.2 \\ \text { 3. } 17.7 & 11.24 .2 & 19 . & 34.7 \\ \text { 4. } 23.1 & 12.17 .7 & 20 . & 34.2 \\ \text { 5. } 23.4 & 13.22 .1 & 21 . & 34.7 \\ 6.21 .9 & 14.50 .0 & 22 . & 34.2 \\ \text { 7. } 21.9 & 15.369 & 23 . & 34.2 \\ \text { 8. } 20.9 & 16.41 .9 & 24 . & 34.7\end{array}$

2

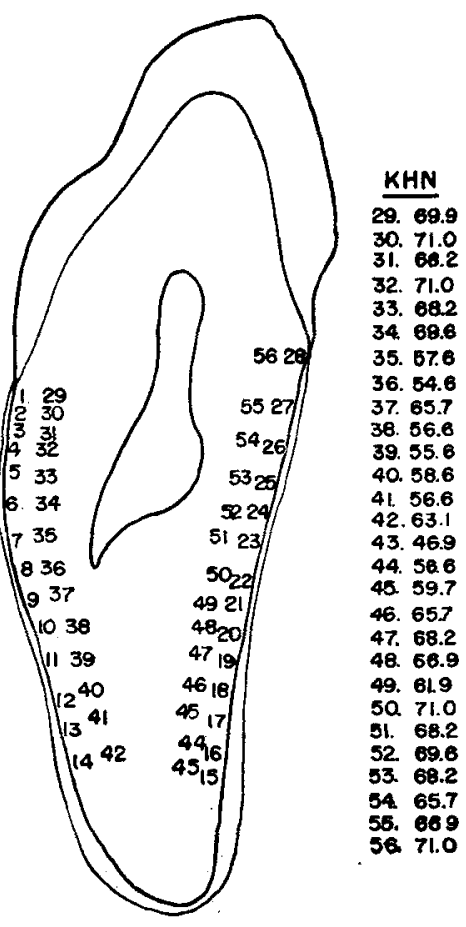




\section{PLATE 2}

\section{EXPLANATION OF FIGURES}

5-6 Microradiographs of areas of internal resorption of root dentin. These lesions were from areas of very little tissue destruction. It is noted that all of the resorption cavities are of similar size and not very large. The numerous radiolucent resorption cavities appear superimposed in those sections $70-100 \mu$ in thickness. No distinct demineralization gradient appears around the sites. (D), Dentin. Orig. Mag. $\times 450$.

7 Microradiograph of an advanced area of internal resorption. In this case much of the root dentin was missing. Larger resorption cavities appear in the remaining dentin than in the cases shown in figures 5 and 6 . The radiopacity is generally uniform except in the center of the picture where secondary sites are noted. Orig. Mag. $\times 100$.

8 Microradiograph of an area of internal resorption located near the apical foramina. Numerous resorption cavities appear along the walls of this deep defect which may be an accessory root canal. Orig. Mag. $\times 100$. 

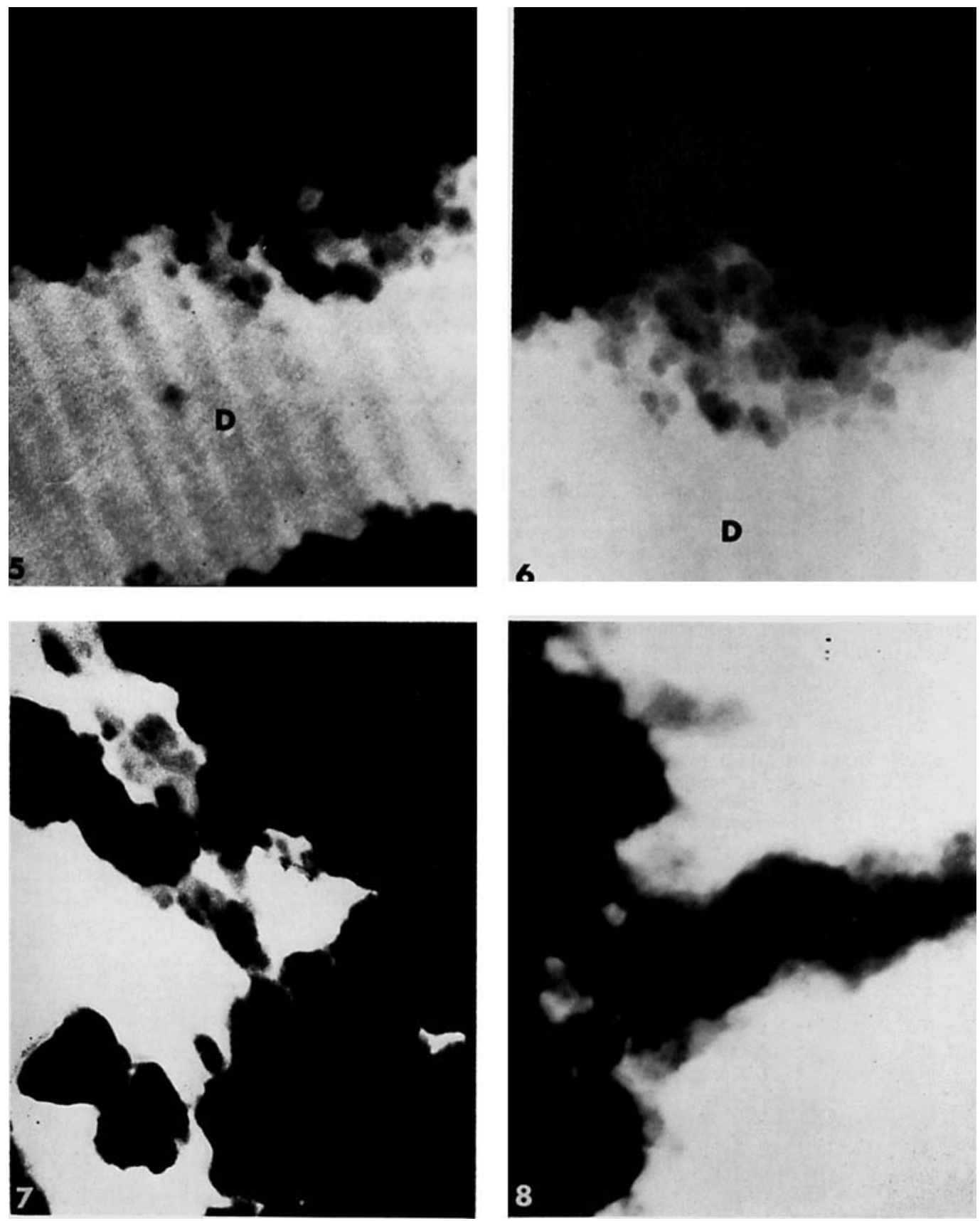
PLATE 3

EXPLANATION OF FIGURES

9 A resorption site which originated along the pulpal aspect of a human tooth. The dentinal tubules are visible as is the ragged edge of the resorption front. No mineralization gradient is seen. An area of bony repair can be seen partially filling a defect, ( $R$ ), Repair. Orig. Mag. $\times 100$.

10 A resorption site located on the external aspect of a tooth. The areas of repair appear extensive. It is probable that this bone or cementum has also undergone some resorption with a cavity resulting in the central area of the secondary deposition. Orig. Mag. $\times 100$.

11 A microradiograph of a resorption site originating from the internal aspect of a tooth. The dentin tubules are faintly visible as is an area of radiolucent matrix. This appears as an area of decreased mineral content. Because of its location it is possible that this area represents predentin. Orig. Mag. $\times 540$.

12 A diagram of a resorption front in dentin representing an interpretation of the microradiographic data. The relationship of the dentinal tubules and the numerous lacunar sites are shown. Each site is connected with another as well as to the surface of the primary site. As the oval shaped sites are expanded they isolate small islands of dentin which in turn are then finally resorbed. 
MINERAL DENSITY AT RESORPTION SITES IN TEETH

J. K. Avery, R. A. Meyers and L. E. Hale

PLATE 3
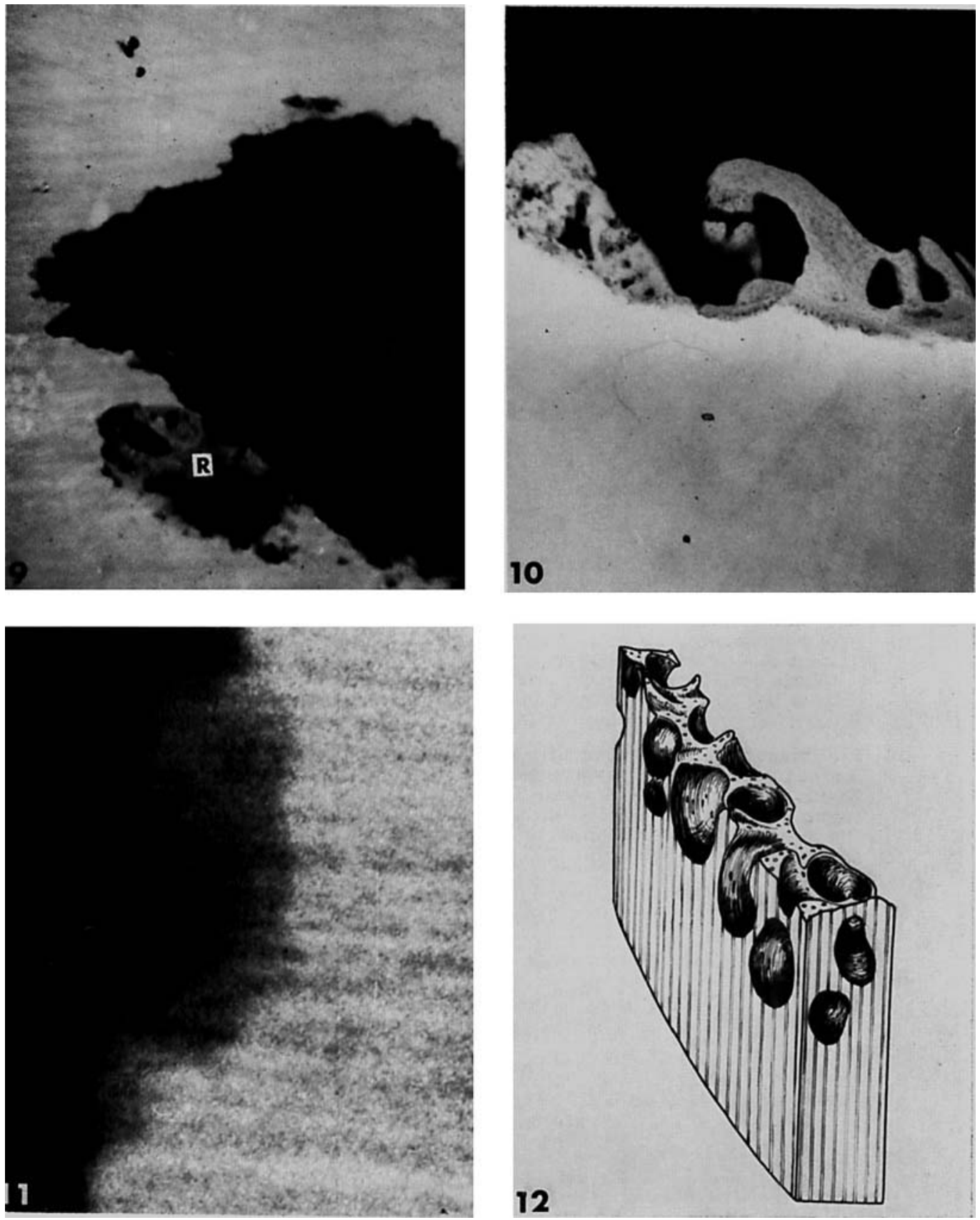
PLATE 4

EXPLANATION OF FIGURES

13 Photomicrograph of an initial or early site of internal resorption revealing a loss of some predentin. The odontoblasts have degenerated and the degenerative changes in the pulpal connective tissue can be seen. Some predentin, but not dentin, has already been destroyed. Vascular granulation tissue has invaded this area adjacent to a site of amputation of the pulp with calcium hydroxide. This amputation was done necessarily to remove a necrotic area of the pulp. (P), Predentin, (D), Dentin. Hematoxylin and eosin stain. Orig. Mag. $\times 450$.

14 Photomicrograph of an area of internal resorption revealing a dense staining of the matrix immediately adjacent to the resorption front to a depth of several microns. This may be indicative of chemical changes related to the resorption process such as demineralization of the matrix. Mallory's connective tissue stain. Orig. Mag. $\times 450$.

15 Photomicrograph of an area of internal resorption showing the dentinal tubules in cross section and a remaining spicule of dentin and attached predentin, ( $P$ ), predentin and (arrows) indicating predentin. The normal architecture of the pulp is lost and some large multinucleated cells appear along the resorption front. Hematoxylin and eosin stain. Orig. Mag. $\times 450$.

16 Photomicrograph of an area of active internal resorption. The cross sectioned dentin tubules and the lacunar resorption sites can be seen. Note the cells and fibrous appearing material within the lacunae. Below can be seen a spicule of dentin and adjacent attached predentin, (P), Predentin, and (arrows) indicating predentin. It would appear as if the resorption front is skirting this area. Hematoxylin and eosin stain. Orig. Mag. $\times 450$. 

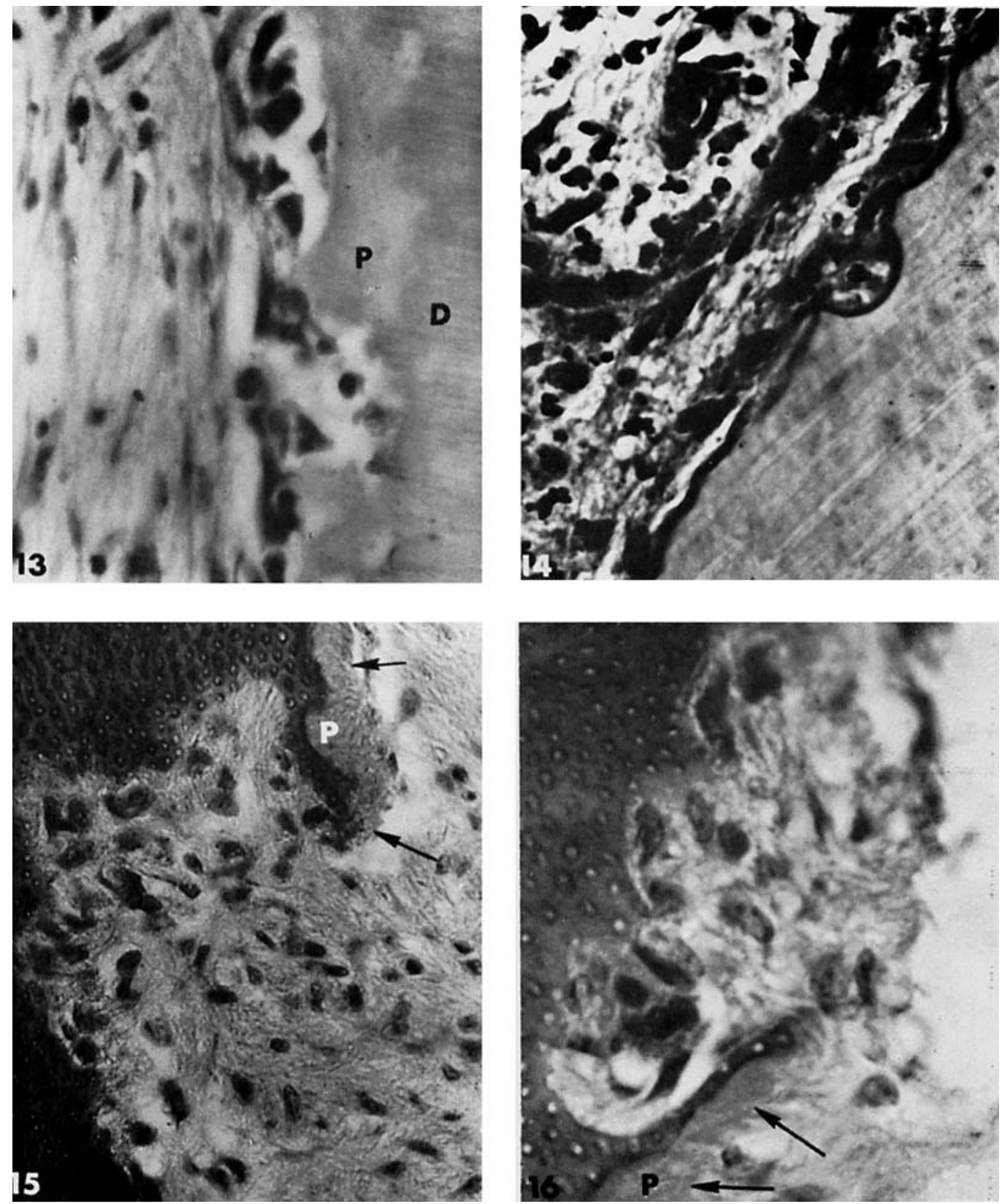